\title{
Sclerotherapy for Varicose Veins of the Lower Limbs
}

\author{
Papa Adama Dieng*, Magaye Gaye, Ndeye Fatou Sow, Modibo Doumbia, Souleymane Diatta, \\ Momar Sokhna Diop, Papa Amath Diagne, Amadou Gabriel Ciss \\ Cardiovascular Center at Fann University Hospital, Dakar, Senegal \\ Email:*padiengsala@yahoo.fr
}

How to cite this paper: Dieng, P.A., Gaye, M., Sow, N.F., Doumbia, M., Diatta, S., Diop, M.S., Diagne, P.A. and Ciss, A.G. (2020) Sclerotherapy for Varicose Veins of the Lower Limbs. World Journal of Cardiovascular Surgery, 10, 19-23.

https://doi.org/10.4236/wjcs.2020.102003

Received: January 11, 2020

Accepted: February 10, 2020

Published: February 13, 2020

Copyright $\odot 2020$ by author(s) and Scientific Research Publishing Inc. This work is licensed under the Creative Commons Attribution International License (CC BY 4.0).

http://creativecommons.org/licenses/by/4.0/

\begin{abstract}
Summary: The diagnosis of venous insufficiency is increasing. Multiple techniques are available for its treatment. Chemical sclerotherapy has been performed for over 70 years. The technique improves lately. Objective: This study was conducted to assess early results of foam sclerotherapy in Senegal. Patients and Methods: This is a prospective and descriptive study conducted from January $1^{\text {st }}, 2012$ to December $31^{\text {st }}, 2015$ at cardiovascular center of Fann University hospital in Dakar, Senegal. Foam sclerotherapy was done in 76 patients. Polidocanol was used in concentration of $2 \%$. Sclerotherapy was done several times in patients, every week, as much as needed to occlude varicose veins. We used venous compression in all patients. Results: Foam sclerotherapy sessions permitted to get globally good results. In fact, tight feeling and painful leg disappear in $97 \%$ of patients. Decreases of edema were gotten in $97 \%$ of patients. For leg ulcer, $64 \%$ of complete healing was obtained. The main ulcer healing time was 47 days $(18 ; 72)$. Some minor complications occurred. No major events, such as deep venous thrombosis or pulmonary embolism, were observed. Conclusion: Foam sclerotherapy is an efficient technique for the treatment of varicose veins of the limbs. Also, it opens good perspectives for vein care.
\end{abstract}

\section{Keywords}

Sclerotherapy, Polidocanol, Varicose Vein

\section{Introduction}

Varicose veins diagnosis is improving in Africa [1]. Multiple treatments are possible. Among possible interventions, minimally invasive treatment such as foam sclerotherapy is now routinely used.

Chemical sclerotherapy has been performed for over 70 years [2]. Beside sur- 
gical care sclerotherapy is now an option in treatment of varicose veins of the lower limbs in our center.

The objective of this study was to assess indications and the early results of foam sclerotherapy for varicose veins in Senegal.

\section{Patients and Methods}

This is a prospective and descriptive study conducted from January $1^{\text {st }}, 2012$ to December $31^{\text {st }}, 2015$ at cardiovascular center of Fann University hospital in Dakar, Senegal.

All patients with varicose veins who underwent sclerotherapy are included in the study.

The study was approved by the institutional review board, and informed consent was obtained from all participants.

Foam sclerotherapy was done in 76 patients.

Polidocanol was used in concentration of $2 \%$. For mixture preparation, room air was used as the gas and rapid, manual displacement of the mixture between two syringes joined by a stopcock. These "home made" foams usually employ ratios of gas to liquid 1:3.

Sclerotherapy was done several times in patients, once a week, as much as needed to occlude varicose veins (Table 1), within one month. We used venous compression in all patients.

Patients in this study were diagnosed clinically for varicose veins of the lower limbs (vein dilatation, edema, ulcer), then with Doppler ultrasound for mapping.

Patients had tight leg, varicose veins, edema or ulcer, and superficial or deep reflux.

Patients with leg venous ulcer were $30 \%$.

After closure of sessions, patients' characteristics were collected in Excel form and statistical analyses were performed with the SPSS Statistics software.

Study evaluated epidemiologic results, clinical aspects, indications for sclerotherapy, and early results after foam sclerotherapy.

\section{Results}

Multiple sclerotherapy sessions were done in patients.

The main follow up was 6 months $(3 ; 24)$.

Table 1. Distribution of sclerotherapy sessions in patients.

\begin{tabular}{ccc}
\hline Number of sessions & Number of patients & Percentage (\%) \\
\hline 4 & 10 & 13.15 \\
5 & 24 & 31.57 \\
6 & 27 & 35.52 \\
7 & 10 & 13.15 \\
8 & 5 & 6.57 \\
\hline
\end{tabular}


Foam sclerotherapy sessions permitted to get globally good results (Figure 1, Figure 2). In fact, tight feeling leg and painful leg disappears in $97 \%$ of patients. Decreases of edema were gotten in $97 \%$ of patients, as well varicose veins.

For leg ulcer, $64 \%$ of complete healing was obtained.

The main ulcer healing time was 47 days (18 - 72).

Some complications occurred. Superficial thrombophlebitis occurred in 5 patients (6.57\%). Two patients experienced superficial limited skin necrosis.

After 6 months follow up, 3\% of patients who experienced ulcer healing had a recurrence of disease.

No major events, such as deep venous thrombosis or pulmonary embolism, were observed.

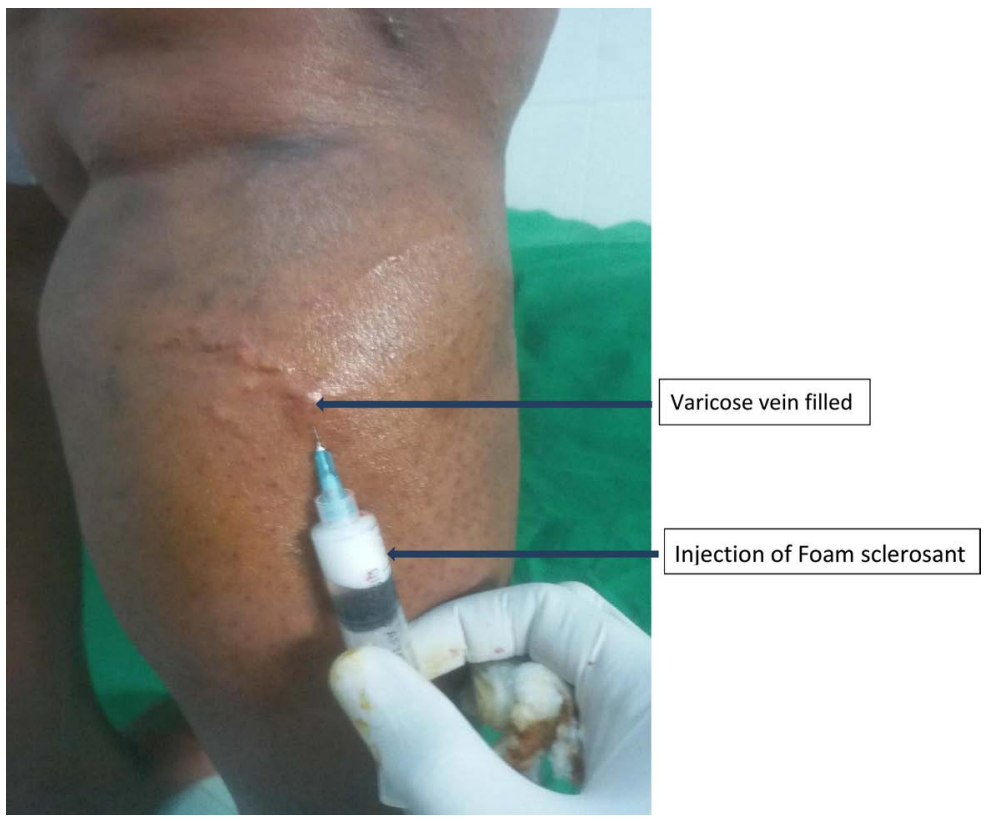

Figure 1. Foam sclerotherapy of varicose vein in lower limb.

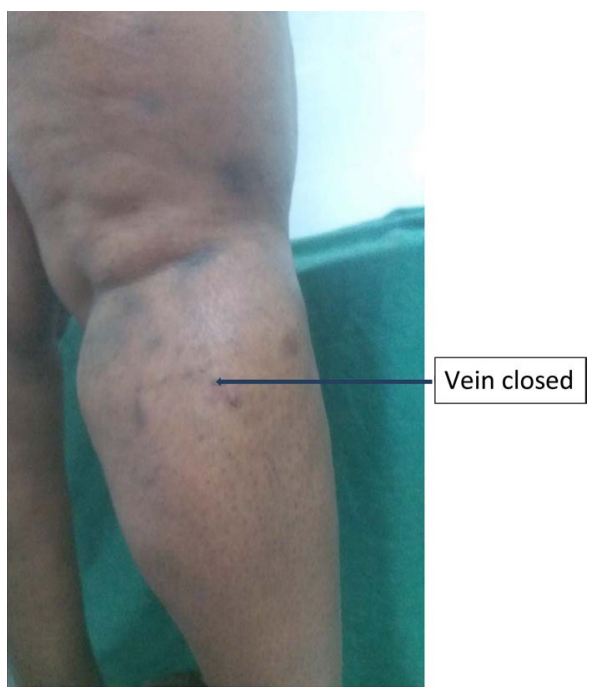

Figure 2. Varicose vein, 1 week after sclerotherapy. 


\section{Discussion}

Foam sclerotherapy is used to treat the varicose veins of the lower limbs. Expected results should be ranged in same rate than other minimally-invasive treatments to be recommended.

Good results require good planning, with respect of the order of the reflux points, working from larger caliber varicose veins to those with smaller caliber [3].

Polidocanol is used as sclerosant because it is well tolerated when delivered either as a liquid or foamed sclerosant [2].

Varicose vein closure may be achieved by direct venous injection of either a liquid or a foamed agent to get endothelial cell damage within affected vessels and thereby stimulate transmural vessel wall damage [4] [5].

Use of liquid is less efficient in term of vein occlusion [6], but symptoms like pain, signs of inflammation and pigmentation, and superficial thrombophlebitis appear more often with foam sclerosis [7].

Rasmussen [8] compared four techniques available for treatment of saphenous vein reflux (intravenous laser ablation, radiofrequency ablation, foam sclerotherapy, and conventional surgery) and observed that the recanalization rate after foam sclerotherapy was approximately $20 \%$, without repercussion for symptoms.

Sclerotherapy is a low-cost, noninvasive treatment, easy accessible in developing countries.

Minor complications occurred with that technique. Also sclerotherapy can be repeated in case of recurrence of venous insufficiency.

This study had some limitations: the non-use of guiding catheter or guidedultrasound procedure. But such techniques are more helpful for sclerotherapy of the Great Saphenous vein.

In perspective, ultrasound-guided sclerotherapy should be recommended for Great Saphenous Vein closure, to have better control, and good results [9] [10].

\section{Conclusion}

Foam sclerotherapy is an efficient technique for the treatment of varicose veins of the limbs. Also, it opens good perspectives for vein care. Sclerotherapy is a low-cost, minimally-invasive and accurate procedure.

\section{Conflicts of Interest}

The authors declare no conflicts of interest regarding the publication of this paper.

\section{References}

[1] Dieng, P.A., Diatta, S., Ba, P.S., Touré, F.B., Ciss, A.G., Gaye, M., Fall, M.L., Diarra, O. and Ndiaye, M. (2014) Traitement chirurgical des varices des membres inférieurs a Dakar: étude rétrospective de 91 cas. Journal Africain de Chirurgie, 3, 23-27.

[2] Eckmann, D.M. (2009) Polidocanol for Endovenous Microfoam Sclerosant Therapy. Expert Opinion Investigational Drugs, 18, 1919-1927. 
https://doi.org/10.1517/13543780903376163

[3] Guex, J.J. (2005) Foam Sclerotherapy: An Overview of Use for Primary Venous Insufficiency. Seminars in Vascular Surgery, 18, 25-29.

https://doi.org/10.1053/j.semvascsurg.2004.12.008

[4] Eckmann, D.M., Kobayashi, S. and Li, M. (2005) Microvascular Embolization Following Polidocanol Microfoam Sclerosant Administration. Dermatologic Surgery, 31, 636-643. https://doi.org/10.1097/00042728-200506000-00004

[5] Parsi, K., Exner, T., Connor, D.E., et al. (2008) The Lytic Effects of Detergent Sclerosants on Erythrocytes, Platelets, Endothelial Cells and Microparticles Are Attenuated by Albumin and Other Plasma Components in Vitro. European Journal of Vascular and Endovascular Surgery, 36, 216-223.

https://doi.org/10.1016/j.ejvs.2008.03.001

[6] Rabe, E., Otto, J., Schliephake, D. and Pannier, F. (2008) Efficacy and Safety of Great Saphenous Vein Sclerotherapy Using Standardised Polidocanol Foam (ESAF): A Randomised Controlled Multicentre Clinical Trial. European Journal of Vascular and Endovascular Surgery, 35, 238-245. https://doi.org/10.1016/j.ejvs.2007.09.006

[7] Davis, L.T. and Duffy, D.M. (1990) Determination of Incidence and Risk-Factors for Postsclerotherapy Telangiectatic Matting of the Lower-Extremity-A Retrospective Analysis. Journal of Dermatologic Surgery and Oncology, 16, 327-330. https://doi.org/10.1111/j.1524-4725.1990.tb00043.x

[8] Rasmussen, L.H., Lawaetz, M., Bjoern, L., et al. (2011) Randomized Clinical Trial Comparing Endovenous Laser Ablation, Radiofrequency Ablation, Foam Sclerotherapy and Surgical Stripping for Great Saphenous Varicose Veins. British Journal of Surgery, 98, 1079-1087. https://doi.org/10.1002/bjs.7555

[9] Myers, K.A., Jolly, D., Clough, A. and Kirwan, J. (2007) Outcome of Ultrasound-Guided Sclerotherapy for Varicose Veins: Medium-Term Results Assessed by Ultrasound Surveillance. European Journal of Vascular and Endovascular Surgery, 33, 116-121. https://doi.org/10.1016/j.ejvs.2006.09.005

[10] Hamel-Desnos, C., Ouvry, P., Benigni, J.P., Boitelle, G., Shadeck, M., Desnos, P., et al. (2007) Comparison of $1 \%$ and 3\% Polidocanol Foam in Ultrasound Guided Sclerotherapy of the Great Saphenous Vein: A Randomised, Double-Blind Trial with 2 Year Follow-Up. European Journal of Vascular and Endovascular Surgery, 34, 723-729. https://doi.org/10.1016/j.ejvs.2007.07.014 